
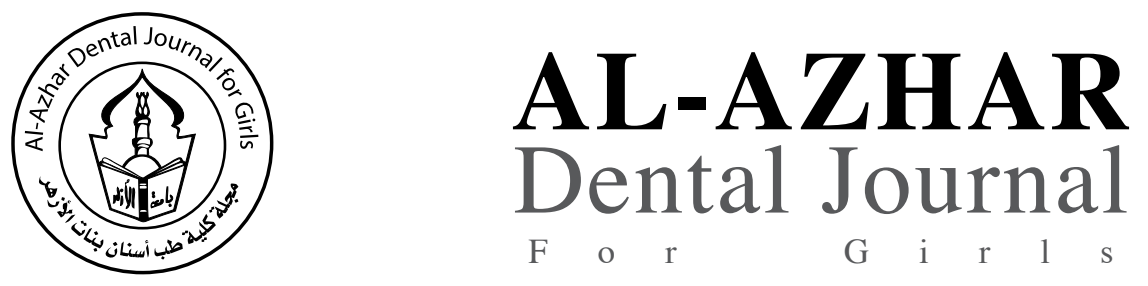

The Official Publication of The Faculty of Dental Medicine For Girls, Al-Azhar University Cairo, Egypt.

ADJ-for Grils, Vol. 4, No. 3, July (2017) — PP. 239:247

\title{
Comparison of Root Canal Transportation and Centering Ability Prepared with Two Single Files Rotary Systems using Cone Beam Computed Tomography Scanning (Ex vivo study)
}

\author{
Asmaa A. El-Hady ${ }^{(1)}$, Mervat I. Fawzy ${ }^{(2)}$ and Hager A. El Naby ${ }^{(3)}$
}

Codex : 29/1707

dentaljournal.forgirls@yahoo.com

\section{KEYWORDS}

Computed tomography, canal

transportation, centering ability,

Twisted File, OneShape, nickel-

titanium instruments

\begin{abstract}
Purpose: The purpose of this study was to compare and evaluate canal transportation and centering ability of 2 single nickel-titanium rotary instruments, one manufactured by twisting (Twisted File) and the other by grinding (OneShape) using ConeBeam Computed Tomography scanning (CBCTs).Materials and Methods: Forty mesiobuccal canals of mandibular molars with an angle of curvature ranging from $25^{\circ}$ to $35^{\circ}$ and radius $<15 \mathrm{~mm}$ were divided according to the instrument used in canal preparation into 2 groups (20 samples each): Group I: instrumented with Twisted File (TF) and Group II: instrumented with OneShape (OS). Each group was subdivided into subgroups (SG) A and B according to the technique of root canal preparation (single or modified). Canals were scanned using an i-CAT CBCT scanner before and after preparation to evaluate the change in the angle and radius of root canal curvature as well as the amount of canal transportation and centering ratio at 1,3 , and $8 \mathrm{~mm}$ from the apex. The significance level was set at $\mathrm{P} \leq 0.05$. Results: At $1 \mathrm{~mm}$ level, TF instruments used with modified technique produced a statistically significant less canal transportation compared to OS instruments $(\mathrm{P} \leq 0.05)$. While at $8 \mathrm{~mm}$ level, OS instruments used with single file technique produced a statistically significant less canal transportation and more centered canal preparation compared to TF instruments $(\mathrm{P} \leq 0.05)$. Conclusions: $\mathrm{TF}$ and OS single files systems used in continuous clockwise rotation are capable of preparing root canals with moderate and sever curvature, with minimal apical transportation. Cervical pre-flaring of the canal has an impact on canal shaping where it enhances the performance of Twisted File instruments. Twisted files with 0.08 tapers could be used for apical preparation without creating severe aberrations.
\end{abstract}

1. Demonstrator, Endodontic Department, Faculty of Dental Medicine for Girls, Al-Azhar University

2. Professor of Endodontics, Endodontic Department, Faculty of Dental Medicine for Girls, AL-Azhar University

3. Associate Professor of Endodontics, Endodontic Department, Faculty of Dental Medicine for Girls, AL-Azhar University 


\section{INTRODUCTION}

Cleaning and shaping of the root canal system have been recognized as the main phase-in root canal treatment ${ }^{(1)}$. The introduction of nickel-titanium (NiTi) rotary instruments has represented a major breakthrough in root canal preparation by permitting easier and faster instrumentation while maintaining the original canal shape with considerably less iatrogenic errors ${ }^{(2)}$. Attempts to improve the quality of curved canal preparation allow the introduction of NiTi instruments with improved mechanical properties through a series of thermomechanical processing procedures, to alter the state of the NiTi alloy into the so-called R-phase of NiTi. This innovative manufacturing process significantly increases instruments' flexibility and cyclic fatigue resistance, allowing them to remain in a central position even in severely curved canals. Recently, single file endodontic concept has been introduced, that is said to require a minimum or no glide path and only a single file can be used for the entire preparation of root canal, irrespective of their diameter, length, or curvature ${ }^{(3,4)}$. Twisted File instrument (TF) manufactured by twisting of the R-phase heat treated NiTi alloy instead of being ground, such as OneShape (OS) instrument that is made of a conventional NiTi alloy are distinctly different in their geometrical design and manufacturing methods.

Twisted File is a non-landed file with a triangular cross section that makes it extremely flexible. It has a variable pitch that minimizes the "screw-in" effect and allows debris to be effectively channeled out of the canal ${ }^{(5)}$.Twisted File has been reported to be the most flexible instrument, with a significant improvement in flexibility ranging from $100 \%$ to $250 \%$, which cut dentin efficiently with more uniform cutting, compared to machined nickeltitanium endodontic files ${ }^{(6,7)}$. Canal transportation and centering ratio has been evaluated in root canals with severe curvature and short radius using (TF), Pathfile-ProTaper (PP) and conventional stainless steel K-files. The results revealed that TF instruments produce significantly less transportation and remain more centered around the original canal. In a subsequent study on extracted mandibular molars with angles of curvature between 25 and 35, TF instruments showed a greater tendency to preserve the canal curvature than $\mathrm{K} 3$ instruments ${ }^{(7-9)}$.

Comparative study was performed to assess, straightening of root canal curvature, apical transportation, loss of working length and the working time for Mtwo and TF instruments in root canals with $30-99^{\circ}$ curvature angles. The instruments were capable of rapidly preparing root canals with moderate and severe curvature, with minimal apical transportation and loss of the working length with no significant difference ${ }^{(10)}$.Cone-beam computed tomography (CBCT) analysis for volumetric changes and transportation of curved root canals following the use of Revo-S (RS), (TF), ProFile GT Series $\mathrm{X}$ (GTX), and ProTaper (PT) was conducted. The results showed that TF system was superior in shaping ability in curved canals, with the instruments remaining more centered and producing less canal transportation than the other systems. However, all tested rotary systems produced canal transportation at the apical and mid-regions of the canal ${ }^{(8)}$. The shaping ability and the time required to prepare curved root canals using Pathfile plus ProTaper Universal versus TF has been evaluated. The two systems showed similar performances regarding the ability to maintain original root canal morphology; however, the preparation time required by the Twisted Files system was shorter ${ }^{(11)}$.

Cone-beam computed tomography was used to evaluate the effects of two different kinematics rotary nickel titanium systems, (TF) a continuous rotation full-sequence system, and WaveOne (WO) a reciprocating single-file system, on transportation, curvature, and volumetric changes of curved root canals. It has been concluded that both TF and WO can be safely used to the full working length, resulting in satisfactory preservation of the original canal shape. However, the results also indicated that the use of the reciprocating motion with WO resulted in increased transportation when compared with the continuous rotation instruments (TF) ${ }^{(12)}$. 
The shaping and centering ability of TF was examined in comparison to HERO Shaper and the Pro-File .06 file systems using simulated curved root canals in plastic blocks. Twisted File showed a better ability to instrument the inner canal wall and remain centered in the apical region ${ }^{(13)}$. The ability of ProTaper Universal, Twisted Files and Mtwo rotary systems to maintain the original root canal anatomy has been evaluated. The results revealed that the ProTaper Universal produced centered preparations while the TF and Mtwo rotary systems produced canal deviation ${ }^{(14)}$.

The unique design of the OS instrument (disparity of cross-sections) provides a finest cutting action in three zones of the canal. The principle following the efficient cutting is that the file has three unusual cross-section zones; in the tip region, the cross- section represents three symmetrical cutting edges, while in the middle of the working part the cross-sectional design progressively changes from an asymmetrical three-cutting-edge design to two cutting edges. At the coronal part, the S-shaped cross section shows two symmetrical cutting edges, resembling the cross-sectional design of Reciproc instrument ${ }^{(15)}$. One Shape's flexibility and unique downward movement ensures a highly effective apical progression that respects the original canal path and curvature. Also, the uneven pitch of this file reduces instrument screwing effects. OneShape is one of the few single file instruments used in continuous clock-wise rotation for a quick and probably safe root canal preparation ${ }^{(15)}$. In a study using severely curved root canals, deviations of the original root canal geometry were evaluated following the use of (WaveOne, ProTaper and OneShape) systems. The results showed that, amongst all the three filing systems, the OS produced minimum deviation in the original root canal geometry followed by PT and WO at the coronal and middle thirds, while WO showed the least deviation in the root canal geometry at the apical third ${ }^{(16)}$.

The shaping ability of different rotary and reciprocating nickel-titanium file systems (Reciproc,
WaveOne, HyflexCM, F360, and OneShape systems) with and without previous glide path preparation in simulated S-shaped canals were compared. The results revealed that, glide path preparation had no significant impact on canal straightening. Moreover, less tapered instruments (F360, OneShape, and Hyflex CM) maintained the original canal curvature better than instruments having greater tapers (WaveOne and Reciproc) ${ }^{(17)}$. Recently, when the shaping ability of (OS), (RS) and Protaper Next (PTN) was compared, RS instrumentation exhibited superior performance over the OS and PTN systems with respect to transportation and centering ratio ${ }^{(18)}$.

In the comparative study between TF and OS single file rotary system in simulated artificial canals, it was found that, TF respected the original canal curvature and shaped better than OS system ${ }^{(19)}$. Therefore, the aim of the present study was conducted to compare canal transportation and centering ability of two single nickel-titanium rotary instruments, one manufactured by twisting (TF) and the other by grinding (OS) using Cone-Beam Computed Tomography scanning (CBCTs).

\section{MATERIALS AND METHODS}

\section{Samples selection and preparation:}

Mesiobuccal root canals of 40 extracted human mandibular first molars with curvature ranged between $25^{\circ}-35^{\circ}$ according to Schneider's technique (20) and radius $<15 \mathrm{~mm}^{(21)}$ according to Estrela's method ${ }^{(22)}$ were used. All crowns were sectioned at $2 \mathrm{~mm}$ above the cementoenamel junction, and the distal root of all samples was separated at the furcation level. The working length was established using size $10 \mathrm{~K}$-file until it was just visible from the apex, and then $1 \mathrm{~mm}$ was subtracted from this length.

Samples were numerically coded and randomly divided into two experimental groups $(n=20)$ according to the instrument used in canal prepara- 
tion: Group I; instrumented with (TF) and Group II; instrumented with (OS). Each group was subdivided into subgroups $(\mathrm{SG}) \mathrm{A}$ and $\mathrm{B}(\mathrm{n}=10)$ according to the technique of root canal preparation: Subgroup A: Single file technique and Subgroup B: modified technique, where the ENDOFLARE instrument was used first for coronal root canal flaring.

The roots were embedded in a high-precision rubber base impression material (to the level of the cementoenamel junction) that placed in plastic dental arches to ensure close approximation of the preoperative and post- operative images. All samples were scanned before and after instrumentation using the i-CAT CBCT scanner (Imaging Science International, Hatfield, PA). The X-ray field size was $16 \mathrm{~cm}$ diameter $\mathrm{x} 4 \mathrm{~cm}$ height, the exposure time was 26.9 seconds, operating at $120 \mathrm{kV}$ and $5 \mathrm{~mA}$ with slice thickness of $0.125 \mathrm{~mm}$. The acquired data were viewed, and measurements were performed by the invivo5 software (Anatomage, USA). The mesiobuccal canal was traced to determine the angle and radius of root canal curvature. Three cross-section levels at 1,3 , and $8 \mathrm{~mm}$ from the root apex were viewed and dentin thickness was measured around the root canal in four directions; buccal, lingual, mesial and distal.

Measurements were recorded before and after instrumentation to calculate the following: (1) Change in the angle and radius of root canal curvature by calculating the difference between the pre and post instrumentation angles and radii of root canal curvature. (2) The amount of canal transportation at each level by measuring the shortest distance from the edge of pre-instrumented canal to the periphery of the root (mesial and distal) and then comparing these measurements with the same measurements obtained from the instrumented images ${ }^{(9)}$ using the following formula[(m1 $-\mathrm{m} 2)-(\mathrm{d} 1-\mathrm{d} 2)]$. (3) The canal centering ratio at each level according to the following ratio $(\mathrm{m} 1-\mathrm{m} 2) /(\mathrm{d} 1-\mathrm{d} 2)$ or $(\mathrm{d} 1-\mathrm{d} 2)$ / $(\mathrm{m} 1-\mathrm{m} 2)$. where $\mathrm{m} 1$ is the shortest distance from the mesial edge of the root to the mesial edge of the pre-instrumented canal, $\mathrm{d} 1$ is the shortest distance from distal edge of the root to the distal edge of the pre-instrumented canal, $\mathrm{m} 2$ is the shortest distance from the mesial edge of the root to the mesial edge of the instrumented canal, and $\mathrm{d} 2$ is the shortest distance from distal edge of the root to the distal edge of the instrumented canal.

A 17:1 reduction handpiece (ENDOMAX cordless endodontic handpiece) powered by a torquelimited electric motor (ENDOMAXTM); was used at a rotational speed of $442 \mathrm{rpm}$ and a torque-control of $4 \mathrm{~N} / \mathrm{cm}$ for both groups. No glide path was established before instrumentation and all instruments were used with anticurvature techniques. After each instrument use, irrigation with $2 \mathrm{ml}$ of $2.6 \% \mathrm{NaOCl}$ solution using a 31-gauge Navi-Tip flexible irrigation needle was performed and MM-EDTA Cream was used as a lubricating agent.

\section{Statistical Analysis}

Numerical data were explored for normality by checking the distribution of data and using tests of normality (Kolmogorov-Smirnov and Shapiro-Wilk tests). Data were presented as mean and standard deviation (SD), minimum, maximum and 95\% Confidence Interval $(95 \% \mathrm{CI})$ for the mean values. Mann-Whitney U test was used to compare between the two systems as well as to compare between the two preparation techniques. The significance level was set at $\mathrm{P} \leq 0.05$.

\section{RESULTS}

\section{Changes in canal curvature angle and radius:} (Tables 1and 2)

The use of SG IIA resulted in less changes and percent changes in the curvature angle and radius during instrumentation compared to SG IA. However, the difference was not statistically significant $(\mathrm{P}>0.05)$. While the use of SG IB resulted in less changes and percent changes in the curvature angle during instrumentation compared to SG IIB. However, the difference was not statistically significant $(\mathrm{P}>0.05)$. 
Table (1) Descriptive statistics of the mean values of changes $\left({ }^{\circ}\right)$ and $\%$ changes in the curvature angle between the tested instruments

\begin{tabular}{|c|c|c|c|c|}
\hline & Preparation technique & Twisted File & OneShape & \multirow{2}{*}{$\boldsymbol{P}$-value } \\
\cline { 3 - 5 } & & Mean \pm SD & Mean \pm SD & \\
\hline \multirow{2}{*}{ Changes in the curvature angle $\left(^{\circ}\right)$} & Single file technique & $4.36 \pm 3.24$ & $3.89 \pm 2.40$ & 0.658 \\
\cline { 2 - 5 } & Modified technique & $3.76 \pm 3.84$ & $5.00 \pm 3.52$ & 0.205 \\
\hline \multirow{2}{*}{$\%$ changes in the curvature angle } & $\boldsymbol{P}$-value & 0.508 & 0.902 & $12.56 \pm 7.43$ \\
\cline { 2 - 5 } & Single file technique & $14.07 \pm 9.83$ & 0.757 \\
\hline & Modified technique & $12.06 \pm 11.71$ & $16.47 \pm 11.69$ & 0.253 \\
\hline
\end{tabular}

Table (2) Descriptive statistics of the mean values of changes $(\mathrm{mm})$ and $\%$ changes in the curvature radius between the tested instruments

\begin{tabular}{|c|c|c|c|c|}
\hline & Preparation technique & Twisted File & OneShape & \multirow{2}{*}{$\boldsymbol{P}$-value } \\
\cline { 3 - 5 } & & Mean \pm SD & Mean \pm SD & \\
\hline \multirow{2}{*}{ Changes in the curvature radius (mm) } & Single file technique & $2.47 \pm 1.94$ & $1.96 \pm 1.17$ & 0.724 \\
\cline { 2 - 5 } & Modified technique & $1.79 \pm 1.56$ & $2.08 \pm 2.05$ & 0.870 \\
\hline \multirow{2}{*}{$\%$ changes in the curvature radius } & $\boldsymbol{P}$-value & 0.402 & 0.870 & 0.566 \\
\cline { 2 - 5 } & Single file technique & $22.76 \pm 18.98$ & $16.51 \pm 9.14$ & $16.98 \pm 16.56$ \\
\hline & Modified technique & $17.49 \pm 15.05$ & 0.935 \\
\hline
\end{tabular}

\section{Amount of canal transportation:}

At $1 \mathbf{m m}$ level, the results showed that, SG IA $\&$ B produced less canal transportation after instrumentation compared to SG IIA \& B. There was a statistically significant difference between Subgroups I B \& II B, where TF instruments produced less canal transportation $(\mathrm{P} \leq 0.05)$.

At 3mm level, the results showed that, SG IA $\&$ B produced less canal transportation after instrumentation compared to SG IIA \& B with no statistically significant difference $(\mathrm{P}>0.05)$.
At $\mathbf{8 m m}$ level, the results showed that, SG IIA $\&$ B produced less canal transportation after instrumentation compared to SG IA \& B. There was a statistically significant deference between Subgroups I A \& II A, where OS instruments produced less canal transportation $(\mathrm{P} \leq 0.05)$ (Fig. 1).

\section{Centering Ratio:}

At $1 \mathrm{~mm}$ level, the results showed that, SG IA \& B produced more centered canal preparation compared to SG IIA \& B. However, the difference was not statistically significant $(\mathrm{P}>0.05)$. 
At 3mm level, the results showed that, SG IA produced more centered canal preparation compared to SG IIA. While, the results showed that, SG IIB produced more centered canal preparation compared to SG IB. However, the difference was not statistically significant $(\mathrm{P}>0.05)$.

At $\mathbf{8 m m}$ level, the results showed that, SG IIA $\& \mathrm{~B}$ produced more centered canal preparation compared to SG IA \& B. There was a statistically significant deference between subgroups I A \& II A, where OS instruments produced more centered canal preparation compared to TF instruments $(\mathrm{P} \leq$ 0.05) (Fig. 2).

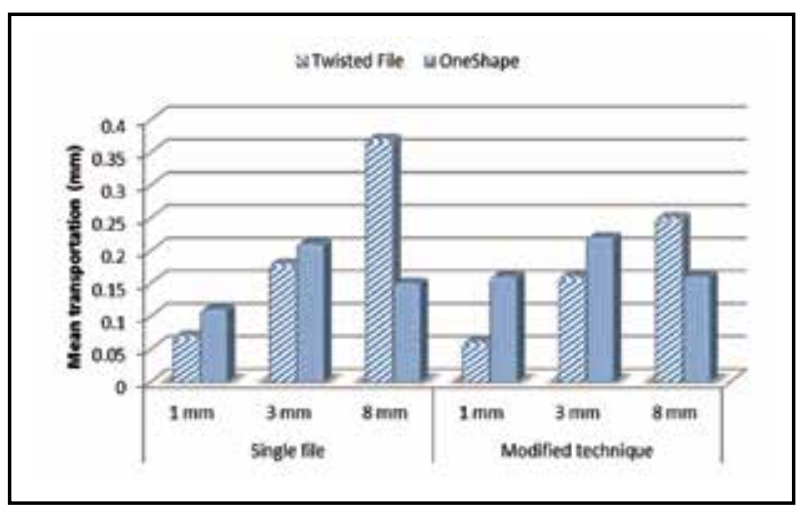

Fig. (1) A bar chart comparing the mean canal transportation after using TF and OS instruments with single file and modified techniques (SG IA \& B) and (SG IIA \& B).

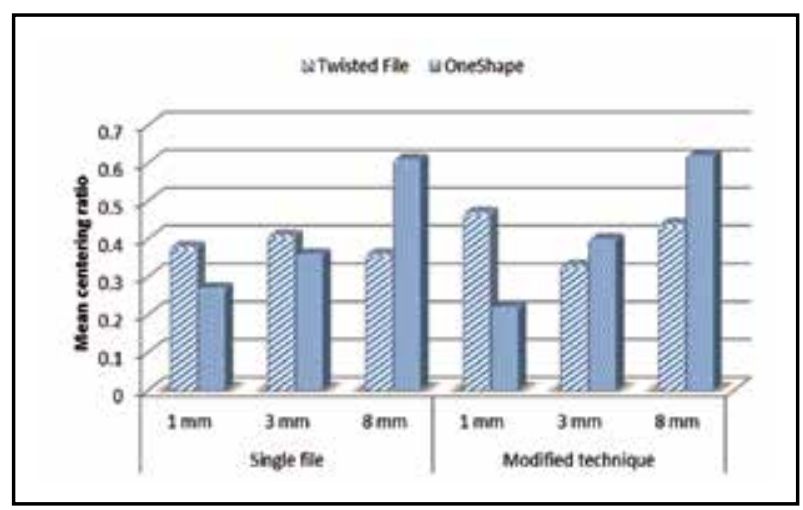

Fig. (2) A bar chart comparing the mean centering ratio after using TF and OS instruments with single file and modified techniques (SG IA vs. IIA) \& (SG IB vs. IIB).

\section{DISCUSSION}

The introduction of NiTi instruments allowed a safer and easier preparation of canals with complex anatomic characteristics; however, their cutting ability is a complex interrelationship of different parameters such as the cross-sectional design, pitch and helical angle, metallurgical properties, and surface treatment of the instrument ${ }^{(9)}$. Twisted File (TF) and OneShape (OS) instruments are recently introduced file systems that are distinctly different in their geometrical design and manufacturing methods. Therefore, the aim of this study was conducted to compare canal transportation and centering ability of two single nickel-titanium rotary instruments. One of these instruments is manufactured by twisting (Twisted File) and the other by grinding (One Shape) using CBCT scanning.

An extracted human teeth model was used in this study as testing rotary NiTi file systems under realistic circumstances in natural dentin is considered more beneficial than in simulated acrylic canals, where acrylic resin is not an optimal material for testing rotary instruments because it does not reproduce the microhardness of dentin and the frequently encountered anatomic variations cannot be easily simulated ${ }^{(8,10)}$. Three levels $(1,3$, and 8 $\mathrm{mm}$ from the root apex) were chosen representing the apical and middle thirds of root canal in which curvatures highly susceptible to iatrogenic mishaps ${ }^{\left({ }^{8}\right)}$. Noninvasive CBCT scanning was used as it provides an accurate, reproducible, 3-dimensional evaluation of changes in root canal morphology before and after preparation without destruction of the specimens ${ }^{(12,14)}$.

In the present study, the results of the mean value and standard deviation of the changes in the curvature angle and radius for SG IA \& IIA showed that, the use of OS instruments resulted in less changes and percent changes in the curvature angle and radius during instrumentation compared to TF instruments. However, the difference was not statistically significant $(\mathrm{P}>0.05)$. This finding could be attrib- 
uted to noncutting tips that both instruments have, which work with minimal apical pressure and function only as a guide to allow easy penetration ${ }^{(17)}$. The 3 different cross-section zones of the OS instrument intended to facilitate canal penetration by a snake-like movement and upward removal of debris; Accordingly, leading to uniform removal of dentin and less stress on the instrument, thus causing less transportation ${ }^{(8,23)}$.

The lower degree of changes in the angle and radius of curvature with OS instruments reported in this study corporates the findings of previous studies, which revealed that, OS instruments produced minimum deviation in the original root canal geometry ${ }^{(16-18)}$.On the other hand, the results of the present study were in disagreement with a recent study reported that, TF respected the original canal curvature and shaped better than OS system ${ }^{(19)}$. This might be attributed to the use of simulated artificial canals rather than extracted teeth model.

The mean and standard deviation of the changes in the curvature angle and radius for SG IB \& IIB showed that, the use of TF instruments resulted in less changes and percent changes in the curvature angle and radius during instrumentation compared to OS instruments. However, the difference was not statistically significant $(\mathrm{P}>0.05)$. The lower degree of changes in the angle and radius of curvature produced by TF could be attributed to the cervical pre-flaring, which reduces the instrument's friction with the root canal walls. In addition, the new manufacturing method of the TF instruments (R-phase heat treatment, twisting of the metal, and the surface deoxidation), resulting in increased phase transformation temperatures and increased flexibility of TF files compared with the other NiTi instruments manufactured by grinding as OS file instrument $^{(4,6,19,24-26)}$.

The results of the present study regarding the performance of $\mathrm{TF}$ instrument in modified technique was consistent with previous studies ${ }^{(7-9,27)}$, which reported that $\mathrm{TF}$ system cut dentin efficiently with more uniform cutting and greater tendency to preserve the canal curvature compared to instruments manufactured by grinding.

In the present study, both TF and OS single files rotary systems resulted in slight canal transportation at all examined levels (1, 3 and $8 \mathrm{~mm}$ from the root apex). Twisted File instruments recorded lower mean canal transportation compared to OS instruments at 1 and $3 \mathrm{~mm}$ levels either using single or modified technique, with a statistically significant difference at $1 \mathrm{~mm}$ level in the modified technique $(\mathrm{P} \leq 0.05)$. This could be attributed to the cervical pre-flaring that was applied in the modified technique which allows preservation of a pathway to the full working length, thus avoiding excessive binding in the canal ${ }^{(28)}$. Moreover, the files enter the root canal more freely and only part of the file works within the root canal resulting in minor friction with less incidence of apical transportation ${ }^{(29)}$. Also, the superior flexibility of the TF instruments resulting from R-phase heat treatment might improve its effect at these levels ${ }^{(5,7)}$.

The result of canal transportation that recorded in the present study are supported by the results of centering ratio, where TF instruments produced higher mean centering ratio compared to OS instruments at $1 \mathrm{~mm}$ level either using single or modified technique.

The results of canal transportation of TF instruments were comparable to the results obtained with previous study, in which TF was capable of preparing root canals with moderate and severe curvature, with minimal apical transportation compared to Mtwo instruments ${ }^{(10)}$. Moreover, many authors reported that the TF instruments maintain the original root anatomy in curved canals and were able of producing centered preparations ${ }^{(7-9,27)}$.

At $8 \mathrm{~mm}$ level from the root apex, OS instruments recorded significantly lower mean canal transportation as well as higher mean centering ratio compared to TF instruments following root canal preparation with the single file technique 
$(\mathrm{P} \leq 0.05)$. This could be due to the use of 0.06 taper of OS instruments compared to 0.08 taper of TF instruments. Moreover, the asymmetrical cutting profile of OS at $8 \mathrm{~mm}$ facilitates penetration by a snake like movement and offers a root canal shaping that is closely adapted to the anatomical criteria of the canal ${ }^{(8)}$. Such results are comparable to that obtained with a recent study ${ }^{(30)}$.

It has been concluded that apical transportation greater than $0.3 \mathrm{~mm}$ may have a negative effect on the apical seal during obturation ${ }^{(31)}$. In the present study, none of the tested groups exceeded this limit at 1 and $3 \mathrm{~mm}$ levels from the root apex. This is in consistence with previous studies using TF $(9,8,27)$ and OS instruments ${ }^{(15,16)}$.

\section{CONCLUSION}

Within the limitations of this study the following could be concluded:

1. Twisted File and OneShape single files systems used in continuous clockwise rotation are capable of preparing root canals with moderate and sever curvature, with minimal apical transportation.

2. Cervical pre-flaring of the canal has an impact on canal shaping where it enhances the performance of Twisted File instruments.

3. Twisted files with 0.08 tapers could be used for apical preparation without creating severe aberrations.

Further investigations are recommended to assess the impact of using Twisted File modified technique compared to the previously established full sequence Twisted File instruments.

\section{REFERENCES}

1. Schilder H. Cleaning and shaping the root canal. Dent Clin North Am. 1974; 18(2):269-96.

2. Walia H, Brantley WA, Gerstein H. An initial investigation of the bending and torsional properties of nitinol root canal files. J Endod. 1988; 14(7):346-51.
3. Yared G. Canal preparation using only one Ni-Ti rotary instrument: preliminary observations. Int Endod J. 2008; 41(4):339-44.

4. Ruddle CJ. Endodontic Canal Preparation: single-file shaping technique. Dent Today. 2012; 31(1):124, 126-9.

5. Richard EM. Blended endodontic elegance and simplicity: the single twisted file preparation and matching Real Seal one obturator: Int Dent SA. 2010; 12(3):40-8.

6. Gambarini G, Grande NM, Plotino G, Somma F, Garala M, De Luca M, Testarelli L. Fatigue resistance of enginedriven rotary nickel-titanium instruments produced by new manufacturing methods. J Endod. 2008; 34(8):1003-5.

7. Fayyad DM and Elhakim Elgendy AA. Cutting efficiency of twisted versus machined nickel-titanium endodontic files. J Endod. 2011; 37(8):1143-6.

8. Hashem AAR, Ghoneim AG, Lutfy RA, Foda MY, Omar GAF. Geometric analysis of root canals prepared by four rotary NiTi shaping systems. J Endod. 2012; 38(7):996-1000.

9. Gergi R, Rjeily JA, Sader J, Naaman A. Comparison of Canal Transportation and Centering Ability of Twisted Files, Pathfile-ProTaper System, and Stainless Steel Hand K-Files by Using Computed Tomography. J Endod. 2010; 36(5):904-7.

10. Urro Torres D, González Rodríguez P, Ferrer C. Shaping ability of Mtwo and Twisted File rotary systems in curved root canals. J Clin Exp Dent. 2012; 4(5):e275-80.

11. Rocha DGP, Alves VdO, De Martin AS, Fontana CE, Cunha RS, Bueno CEdS. Comparison of preparation time and ability to maintain canal morphology in curved canals: Pathfile+ Protaper Universal versus Twisted Files. Rev Odontol UNESP. 2013; 42(2):99-103.

12. Marzouk AM and Ghoneim AG. Computed tomographic evaluation of canal shape instrumented by different kinematics rotary nickel- titanium systems. J Endod 2013; 39: 906-9.

13. Love RM and Masi OV. Shaping Ability of Twisted File, HERO Shaper and Profile. 06 Ni-Ti Instruments in Simulated Curved Root Canals. Dentistry. 2013;3(3):171-175.

14. Aguiar CM, Donida FA, Câmara AC, Frazão M. Changes in root canal anatomy using three nickel-titanium rotary system: a cone beam computed tomography analysis. Braz J Oral Sci. 2013; 12(4):307-12.

15. Christian RG. OneShape - a single file NiTi system for root canal instrumentation used in continuous rotation. ENDO (Lond Engl) 2013; 7(3):211-16. 
16. Patil A and Aggarwal S. To compare and contrast maintenance of root canal geometry using rotary $\mathrm{NiTi}$ systems - An in vitro study. Endodontol. 2013; 25(1): 14-21.

17. Bürklein S, Poschmann T, Schäfer E. Shaping Ability of Different Nickel-Titanium Systems in Simulated S-shaped Canals with and without Glide Path. J Endod. 2014; 40(8):1231-4.

18. Jain D, Medha A, Patil N, Kadam N, Yadav V, Jagadale H. Shaping ability of the fifth generation ni-ti rotary systems for root canal preparation in curved root canals using conebeam computed tomographic: an in vitro study. J Int Oral Health. 2015; 7(Suppl 1): 57-61.

19. Reddy PJ, Kumar VS, Aravind K, Kumar HT. Canal Shaping with One Shape File and Twisted Files: A Comparative Study. J Clin Diagn Res. 2014;8(12):ZF01-3.

20. Schneider SW. A comparison of canal preparations in straight and curved root canals. Oral Surg Oral Med Oral Pathol. 1971; 32(2):271-5.

21. Pangica AM, Biclesanu C, Florescu A. Methods for evaluation of root canal curvatures. In International Symposium on Biomedical Engineering and Medical Physics, Riga, Latvia 2013 (pp. 159-162). Springer Berlin Heidelberg.

22. Estrela C, Bueno MR, Sousa-Neto MD, Pécora JD. Method for determination of root curvature radius using cone-beam computed tomography images. Braz Dent J. 2008;19(2):114-8.

23. Bürklein S, Börjes L, Schäfer E. Comparison of preparation of curved root canals with Hyflex CM and Revo-S rotary nickel-titanium instruments. Int Endod J. 2014; 47(5): 470-6.
24. Shen Y, Zhou HM, Zheng YF, Peng B, Haapasalo M. Current challenges and concepts of the thermomechanical treatment of nickel-titanium instruments. J Endod. 2013; 39(2):163-72.

25. Gambarini G, Grande NM, Plotino G, Somma F, Garala M, De Luca M, Testarelli L. Fatigue resistance of enginedriven rotary nickel-titanium instruments produced by new manufacturing methods. J Endod. 2008; 34(8):1003-5.

26. Yahata Y, Yoneyama T, Hayashi Y, Ebihara A, Doi H, Hanawa T, Suda H. Effect of heat treatment on transformation temperatures and bending properties of nickel-titanium endodontic instruments. Int Endod J. 2009; 42(7):621-6.

27. El Batouty KM and Elmallah WE. Comparison of canal transportation and changes in canal curvature of two nickel titanium rotary instruments. J Endod. 2011; 37(9):1290-2.

28. Zanette F, Grazziotin-Soares R, Flores ME, et al. Apical root canal transportation and remaining dentin thickness associated with ProTaper universal with and without PathFile. J Endod 2014; 40:688-93.

29. Song YL, Bian Z, Fan B, Gutman JL, Peng B. A comparison of instrument-centering ability within the root canal for three contemporary instrumentation techniques. Int Endod J. 2004; 37(4):265-71.

30. Capar ID, Ertas H, Ok E, Arslan H, Ertas ET. Comparative study of different novel nickel-titanium rotary systems for root canal preparation in severely curved root canals. J Endod. 2014; 40:852-6.

31. Wu MK, Fan B, Wesselink PR. Leakage along apical root fillings in curved root canals. Part I: effects of apical transportation on seal of root fillings. J Endod. 2000;26(4):210-6. 